Thorax (1966), 21, 391.

\title{
Profound hypothermia with prolonged circulatory arrest
}

\author{
An experimental study 1
}

\author{
J. B. JOHNSTON, C. USHIRO, K. H. FINLEY, AND \\ F. G E R B ODE
}

From the Service of Cardiovascular Surgery and the Department of Neurology, Presbyterian

Medical Center, San Francisco, and the Department of Cardio-pulmonary Surgery, University of New South Wales, Sydney

The technique of biventricular bypass with the induction of profound hypothermia and circulatory arrest has been practised widely as a means of performing open-heart surgery since it was introduced in 1959 (Drew and Anderson, 1959; Shields and Lewis, 1959; Gordon, Jones, Luddington, and Meyer, 1960).

One of the limiting factors, using this technique in open-heart surgery, is that 50 to 60 minutes only of circulatory arrest will be tolerated at $10^{\circ} \mathrm{C}$. This may mean that too little time is available for completion of the intracardiac repair. This limitation has been overcome to some extent by recommencing the circulation for a short period, after which a further period of circulatory arrest is available. There is still a paucity of information as to how the body tolerates repeated periods of circulatory arrest.

Another aspect of this method which is controversial is whether temporary or permanent neurological damage may occur in patients subjected to profound hypothermia with or without circulatory arrest. Thus Dubost, Blondeau, and Piwnica (1962) reported no neurological sequelae in a large experience. Drew (1961), who has used the method consistently since 1959 , has noted only occasional post-operative neurological difficulties. Björk and Hultquist (1960, 1962), and Egerton, Egerton, and Kay (1963), on the other hand, observed a high incidence of neurological complications, with frequent deaths from this cause, in a small series of patients operated upon with profound hypothermia with or without arrest of the circulation.

The following studies were undertaken in an attempt to define some of the potentials and

1Supported in part by research grant HE 06311 from the National Institutes of Health, United States Public Health Service limitations of the method of profound hypothermia with or without circulatory arrest. A superficial examination of the problem showed that there were at least three potentially harmful factors-namely, profound hypothermia per se, circulatory arrest, and the effect of progressive hypoxia. The experimental model was designed in an attempt to separate the effects of these three factors, and with the object of testing each to the limits of endurance. It was hoped that some information regarding their relative Importance could be obtained by studying the survival rates, by analysing the cause of death in animals which did not survive, and by carrying out a neurohistological examination of the brains of all chronically surviving animals.

\section{EQUIPMENT}

The apparatus used originally by Drew, Keen, and Benazon (1959) was modified with the object of simplifying the technique (Fig. 1).

1. The rigid plastic reservoirs were replaced with plastic blood-collecting bags from which all air had been evacuated. This eliminated the possibility of air embolism.

2. A single DeBakey type roller pump with two channels, to take both the right and left circuits, was used. It was found that soon after going on bypass the flows in the right and left systems became equal, and both circuits could be controlled with a single pump during cooling and re-warming.

3. A simple, disposable heat-exchanger was used in the left circuit.

4. A cross-connexion was established between the right and left reservoirs. This had two objects. In the first place, during the early stages of bypass when the flows were not quite equal, the levels in the reservoirs could be balanced. Secondly, when it was desired to perform a veno-arterial perfusion, without 


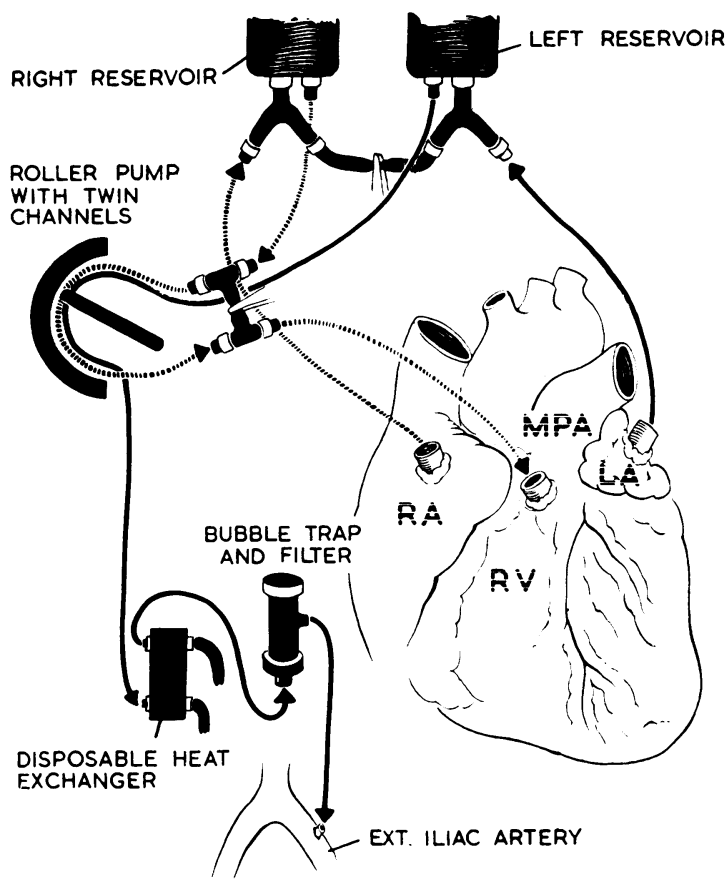

FIG. 1. Diagram illustrating circuits for profound hypothermia with autogenous oxygenation (modified from Drew).

oxygenation, as in the fourth group of experiments. this could be done with ease by the application of clamps in suitable positions.

5. Finally, a cross-connexion was inserted between the two limbs of the right circuit going into and coming out of the roller pump. This was required as a bypass during veno-arterial circulation when the pulmonary artery was not being perfused.

\section{METHOD}

The apparatus was primed with $1,200 \mathrm{ml}$. blood obtained from a mongrel dog which had been anaesthetized with a minimal dose of sodium thiopentone and succinyl choline to permit intubation. Heparin. $3 \mathrm{mg} . / \mathrm{kg}$. body weight. was injected into the animal before exsanguination.

Mongrel dogs, weighing between 11 and $25 \mathrm{~kg}$., were anaesthetized with $30 \mathrm{mg} . / \mathrm{kg}$. sodium nembutal injected intravenously. After intubation with the largest possible Magill's endotracheal tube the animals were connected to a Palmer respirator and mechanically ventilated. Respiration was continued during cooling until circulatory arrest and was recommenced when re-warming was started. Ventilation, with a mixture of $95 \%$ oxygen and $5 \%$ carbon dioxide, was used in all the experiments. The animal was then placed in the right lateral position. Initially, the pelvis was tilted to give access to both groins, but, as soon as the cannulations had been performed, the legs were $\frac{\bar{c}}{\overline{0}}$. released to avoid over-stretching the hind limbs. The right femoral artery and vein were cannulated andฉ̊ connected to mercury and water manometers respec-» tively to record arterial and venous pressures. The left iliac artery was exposed. The chest was then? opened through a left lateral thoracotomy, stripping the upper border of the fifth rib. The pericardiumw was incised widely, and the right and left atrial appendices were cannulated with metal cannulae fol-x lowed by cannulation of the right ventricular outflow tract. The left external iliac artery was cannulateder in retrograde fashion. Before cannulation the animale received intravenously $3 \mathrm{mg}$. heparin $/ \mathrm{kg}$. and in prolonged experiments supplementary doses ofo heparin were given. Meanwhile, the apparatus had been primed. and appropriate connexions were madecs to these two circuits. Thermistor probes had beend inserted into the pharynx, into the oesophagus, and $\mathbb{\mathbb { D }}^{+}$ into the rectum and also into the inflow and outflow lines to and from the heat exchanger. These tempera- $\frac{\Phi}{6}$ tures were monitored continuously throughout the experiment. In addition, in several expe-iments the pulmonary artery and the left atrial pressures wereos monitored.

Left bypass was then begun at a flow rate of between 10 and $20 \mathrm{ml} . / \mathrm{kg}$., and this was gradually increased. Throughout cooling and re-warming theo temperature differential between the inflow and out-⿳亠丷厂 flow lines of the heat exchanger was never allowed to̊ exceed $10^{\circ} \mathrm{C}$. At approximately $30^{\circ} \mathrm{C}$, the right by $-\overrightarrow{\overrightarrow{2}}$ pass was begun, and cooling was allowed to progress 3 until a temperature of $10^{\circ}$ or $15^{\circ} \mathrm{C}$. pharyngeal was obtained. In some of the experiments circulation was? then arrested for a certain period allowing blood to drain by gravity from the animal, while in others circulation was continued with oxygenation at this low temperature for a definite period. In the thirdx group, veno-arterial circulation was begun. At the end of the prescribed period re-warming was begun. and this was carried out in stepwise fashion until aô temperature of $32^{\circ} \mathrm{C}$. was obtained. The heart was then defibrillated electrically if necessary, and righto heart bypass was discontinued. Left heart bypass was continued until the pharyngeal temperature reached? $37^{\circ} \mathrm{C}$. On the average, cooling proceeded at a rate of slightly less than $1^{\circ} \mathrm{C}$. per minute, and re-warming $\mathcal{N}^{\circ}$ was a little slower. All the cannulae were then re-moved, and the effect of heparin was reversed with $\tilde{O}^{-}$ an injection of hexadimethrene bromide (Polybrene), N $3 \mathrm{mg} . / \mathrm{kg}$. diluted in $100 \mathrm{ml} .5 \%$ dextrose solution, and this was administered slowly.

A drainage tube was inserted into the chest, which? was then closed. When the animal was breathing® spontaneously the endotracheal tube was removed." Blood was administered according to blood loss, and $\frac{0}{7}$ the chest drainage tube was removed on the day after $\frac{}{\mathbb{D}}$ the operation after a chest radiograph had been taken.

Before studying the groups of dogs, it was con- $\stackrel{\mathbb{Q}}{\mathscr{Q}}$ sidered desirable to obtain some information on oxygen consumption at profound hypothermic temperatures. In order to do this. the standard experi-o 
mental preparation was set up and the pharyngeal temperature was lowered to $13^{\circ} \mathrm{C}$. At this temperature oxygenation was ceased by switching to a venoarterial circulation. Repeated estimations of the venous oxygen saturation were then made at varying intervals of time in several dogs by the technique of van Slyke. It was found that after half an hour without oxygenation the venous oxygen saturation dropped from $96 \%$ to an average figure of $55 \%$; after 45 minutes the saturation fell from $94 \%$ to $29 \%$; and after one hour of veno-arterial circulation the saturation dropped from $96 \%$ to $16 \%$ (Fig. 2). In each

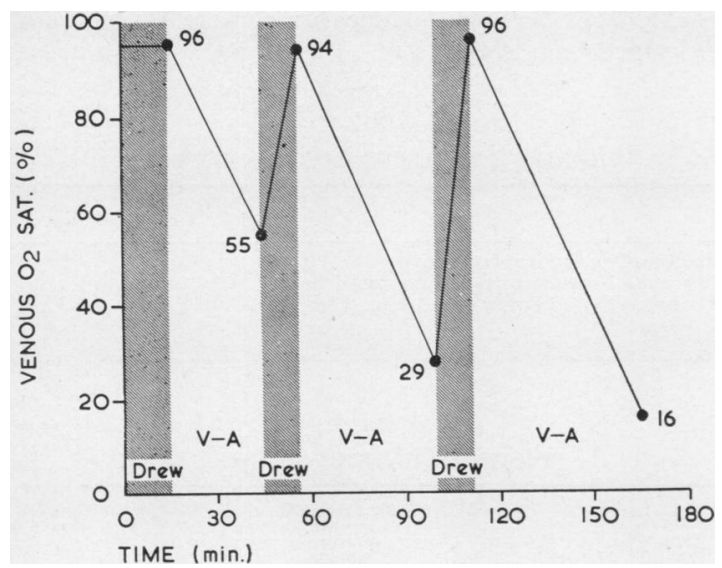

FIG. 2. Illustrates the fall that occurs in the venous oxygen saturation after varying periods without oxygenation at $13^{\circ} C$., during which a veno-arterial $(V-A)$ circulation is continued.

instance it was possible to raise the venous oxygen saturation to over $95 \%$ by reverting to full biventricular bypass with oxygenation for a period of 10 minutes. This proved quite conclusively, if proof were needed, that oxygen consumption does take place at $13^{\circ} \mathrm{C}$. It also provides strong circumstantial evidence that it would be highly undesirable to exceed a period of one hour, with arrest of the circulation, at this temperature.

The following groups of animals were studied (Table I).

GROUP A In five animals the temperature was reduced to $10^{\circ} \mathrm{C}$. The temperature was maintained at this point for three hours before re-warming.

GROUP B In five animals the temperature was reduced to $15^{\circ} \mathrm{C}$. Circulation was then arrested for an hour before re-warming.

GROUP C In six animals the temperature was reduced to $10^{\circ} \mathrm{C}$. Circulatory arrest was then induced for one hour. This was followed by full circulation with oxygenation for $10 \mathrm{~min}$. and then circulation was again arrested for an hour. This manœuvre was repeated once more, so that these animals were subjected to a total period of three hours of circulatory arrest.

GROUP D In the fourth group of animals the temperature was reduced to $10^{\circ} \mathrm{C}$. Veno-arterial circulation was then induced as described above for a period of one hour, and this was succeeded by a 10-minute interval of full bypass with oxygenation. There followed a further hour of veno-arterial circulation before re-warming the animal.

T A B L E I

\begin{tabular}{|c|c|c|c|c|}
\hline Group & Hypothermia & & & No. \\
\hline $\begin{array}{l}\text { A } \\
\text { B } \\
\text { C } \\
\text { D }\end{array}$ & $\begin{array}{l}10^{\circ} \text { C. for } 3 \text { hrs. } \\
15^{\circ} \text { C with circ. arrest }(1 \mathrm{hr} .) \\
10 \text { C. with circ. arrest }(1: 3 \text { hrs. }) \\
10 \text { C. with V-A circ. }(1 \times 2 \text { hrs. })\end{array}$ & $\begin{array}{l}\cdots \\
\cdots \\
\cdots \\
\cdots\end{array}$ & $\begin{array}{l}\cdots \\
\cdots \\
\cdots \\
\cdots\end{array}$ & $\begin{array}{l}5 \\
5 \\
6 \\
9\end{array}$ \\
\hline
\end{tabular}

\section{PREPARATION OF BRAINS IN LONG-TERM SURVIVORS}

The brains of all the dogs listed as long-term survivors were subjected to neurohistological examination by serial section. This involved an examination of approximately 1,000 sections per animal. It was felt that only by such detailed examination could brain damage be positively excluded or included.

In preparing the brain, the animals were anaesthetized with nembutal; both carotid arteries were then exposed and simultaneously injected with formalin acetate. The object of this technique was to avoid pre-mortem anoxia, and it ensured that preservation of the brain started as soon as death had occurred.

The brains of the surviving dogs were then allowed to settle in formalin for three weeks before being embedded in celloidin. They were then sectioned at 25 micra throughout the entire neuraxis and stained with Weigert and Nissl stains respectively (Table VI).

\section{RESULTS}

The results in terms of death or survival are listed in Tables II, III, and IV. Early deaths included all animals which died within 24 hours of the experiment; short-term survivors lived more than 24 hours

T A B L E I I

SURVIVAL

\begin{tabular}{|c|c|c|c|c|c|}
\hline \multirow[b]{2}{*}{ Group } & \multirow[b]{2}{*}{ Hypothermia } & \multirow[b]{2}{*}{ No. } & \multirow[b]{2}{*}{$\begin{array}{l}\text { Early } \\
\text { Deaths }\end{array}$} & \multicolumn{2}{|c|}{ Survivors } \\
\hline & & & & $\begin{array}{l}\text { Short- } \\
\text { term }\end{array}$ & $\begin{array}{l}\text { Long- } \\
\text { term }\end{array}$ \\
\hline $\begin{array}{l}\mathbf{A} \\
\mathbf{B}\end{array}$ & $\begin{array}{l}10^{\circ} \text { C. for } 3 \text { hrs. } \\
\left.15^{\circ} \text { C. with circ. arrest ( } 1 \mathrm{hr} .\right)\end{array}$ & $\begin{array}{l}5 \\
5\end{array}$ & $\begin{array}{l}1 \\
1\end{array}$ & $\begin{array}{l}1 \\
2\end{array}$ & $\begin{array}{l}3 \\
2\end{array}$ \\
\hline C & $\begin{array}{c}10^{\circ} \text { C. with circ. arrest }(1 \times \\
3 \text { hrs. })\end{array}$ & 6 & 6 & 0 & 0 \\
\hline D & $\begin{array}{ccc}10 & \text { C. with } & \mathrm{V}-\mathrm{A} \text { circ. } \\
2 \text { hrs. }) & \ldots & \ldots\end{array}$ & 9 & 5 & 1 & 3 \\
\hline
\end{tabular}


T A B L E I I I

SURVIVAL AND HARMFUL FACTORS

\begin{tabular}{|c|c|c|c|c|}
\hline Group & Hypothermia & & No. & $\begin{array}{l}\text { Short- and } \\
\text { Long-term } \\
\text { Survivors }\end{array}$ \\
\hline $\begin{array}{l}\text { A } \\
\text { B } \\
\text { C } \\
\mathbf{D}\end{array}$ & 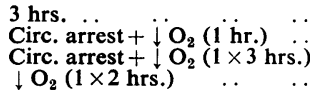 & $\begin{array}{l}\cdots \\
\cdots \\
\cdots\end{array}$ & $\begin{array}{l}5 \\
5 \\
6 \\
9\end{array}$ & $\begin{array}{l}4 \\
4 \\
0 \\
4\end{array}$ \\
\hline
\end{tabular}

T A B L E I V

MODE OF EARLY DEATH

\begin{tabular}{|c|c|c|c|c|}
\hline Group & Hypothermia & No. & Died & \\
\hline $\mathbf{A}$ & $10^{\circ} \mathrm{C}$. for 3 hrs. $\ldots$ & 5 & 1 & Ventricular fibril- \\
\hline$\stackrel{\mathbf{B}}{\mathbf{C}}$ & $\begin{array}{l}15^{\circ} \mathrm{C} \text {. with circ. arrest }(1 \mathrm{hr} .) \\
10^{\circ} \mathrm{C} \text {. with circ. arrest }(1 \times\end{array}$ & 5 & 1 & Pulm. oedema \\
\hline & $\begin{array}{llll}3 \text { hrs.) } \quad \cdots & \cdots & \cdots\end{array}$ & 6 & 6 & $\begin{array}{l}\text { Pulm. oedema } 4 \\
\text { Ventricular } \\
\quad \text { fibrillation } 1, ? 2\end{array}$ \\
\hline D & $\begin{array}{c}10^{\circ} \text { C. with } \text { V-A circ. }(1 \times \\
2 \text { hrs. })\end{array}$ & 9 & 5 & $\begin{array}{ll}\text { Pulm. oedema } & 4 \\
\text { Hypotension } & 1\end{array}$ \\
\hline
\end{tabular}

but died within the first week; long-term survivors lived until the time of sacrifice, which varied from 13 days to 7 months and 19 days.

GROUP A In this group, five animals were subjected to profound hypothermia at $10^{\circ} \mathrm{C}$. for a period of three hours without interruption of circulation, and there were three long-term survivors. One animal could not be defibrillated, and another animal died at 72 hours from pneumonia.

GROUP B Five animals were cooled to $15^{\circ} \mathrm{C}$. in this series of experiments, at which point the circulation was arrested for an hour before re-warming. There were two long-term survivors; there was one early death in an animal which developed pulmonary oedema; two animals died during the first week, one at 7 days, of infection, and the other at 3 days, of pneumonia.

GROUP C In this experiment, six animals had their temperature reduced to $10^{\circ} \mathrm{C}$. and had repeated periods of circulatory arrest with intermittent oxygenation for three hours before re-warming. Four animals died of overwhelming pulmonary oedema which developed during the re-warming phase of the perfusion. The other two were regaining consciousness, a few hours after the operation had ended, when they developed irreversible ventricular fibrillation. There were no long-term survivors in this group.

GRoUP D In this group of nine animals, the temperature was reduced to $10^{\circ} \mathrm{C}$., and this was followed by two periods of veno-arterial circulation, which lasted for one hour with a period of oxygenation interposed. There were three long-term survivors in this experiment. There were five early deaths, four of the animals developed overwhelming pulmonary oedema during the re-warming phase, and one died from progressive hypotension after the experiment had been concluded. One died at 5 days, of infection.

Several dogs showed evidence of hind limb weak- $\varrho$ ness which cleared up after two or three days. None क of the survivors showed any further evidence of $\vec{\circ}$ neurological damage.

\section{RESULTS OF NEUROHISTOLOGICAL EXAMINATION OF BRAINS OF LONG-TERM SURVIVORS}

The brains of the eight long-term surviving dogs, $\overrightarrow{\text { or }}$ together with two controls, were then examined $\omega$ (Table V). Sections of the brain were stained and examined as shown in Table VI. Pathological 0

T A B L E V BRAINS EXAMINED HISTOLOGICALLY

Profound hypothermia $3 \mathrm{hrs}$. Profound hypothermia + circ. arrest $1 \mathrm{hr}$. .. Profound hypothermia $+\mathrm{V}-\mathrm{A}$ circ. 2 hrs. Controls

T A B L E V I

TECHNIQUE OF STAINING

\begin{tabular}{|c|c|c|c|}
\hline \multirow{2}{*}{ Dog. No. } & \multirow{2}{*}{ Group } & \multicolumn{2}{|c|}{ Stain } \\
\hline & & Myelin & Nissl \\
\hline $\begin{array}{ll}\text { J } & 19 \\
\text { J } & 21 \\
\text { J } & 24 \\
\text { J } & 11 \\
\text { J } & 58 \\
\text { J } & 48 \\
\text { J } & 21 \\
\text { J } & 52 \\
\text { J } & 61 \\
\text { J } & 63\end{array}$ & $\begin{array}{c}\text { A } \\
\text { A } \\
\text { A } \\
\text { B } \\
\text { B } \\
\text { D } \\
\text { D } \\
\text { D } \\
\text { Control } \\
\text { Control }\end{array}$ & $\begin{array}{c}\text { Every 10th section } \\
6 \text { th } \\
6 \text { th } \\
10 \text { th } \\
6 \text { th } \\
20 \text { th } \\
20 \text { th } \\
10 \text { th } \\
10 \text { th } \\
10 \text { th }\end{array}$ & $\begin{array}{c}\text { Every } 11 \text { th section } \\
7 \text { th } \\
7 \text { th } \\
11 \text { th } \\
7 \text { th } \\
21 \mathrm{st} \\
21 \mathrm{st} \\
11 \text { th } \\
11 \text { th } \\
11 \text { th }\end{array}$ \\
\hline
\end{tabular}

changes were found in two brains only. Both of these animals belonged to group $A$ and had been subjected to profound hypothermia at $10^{\circ} \mathrm{C}$. with a circulation $\frac{}{5}$ and with continuing oxygenation for a period of three $D$ hours. The changes are illustrated in Figs 3 and 4 and show that there were numerous foci of drop-out of $N$ cells in the granular layer in all regions of the cere- $\sigma$ bellum, with some loss of Purkinje cells in adjacent $N$ areas and some pyknotic changes of the Purkinje N cells. There is no explanation as to why the third $\mathrm{W}$ survivor in this group did not show similar changes unless the size and apparent health of the animal are significant. The two dogs showing pathological changes in the cerebellum weighed 12 and $11.4 \mathrm{~kg} . \stackrel{?}{?}$ at surgery and gained $2 \mathrm{~kg}$. and $0.4 \mathrm{~kg}$. respectively $\square$ in the ensuing five months after the experiment until $\overrightarrow{0}$ they were sacrificed. The third dog in this group $\mathbb{\mathbb { D }}$ weighed $19 \cdot 1 \mathrm{~kg}$. and gained $10 \mathrm{~kg}$. in the five and $\mathrm{a} \underset{\mathrm{D}}{\mathrm{D}}$ half months' interval between the experiment and $\varrho$ sacrifice. The two animals exhibiting these neuro- 


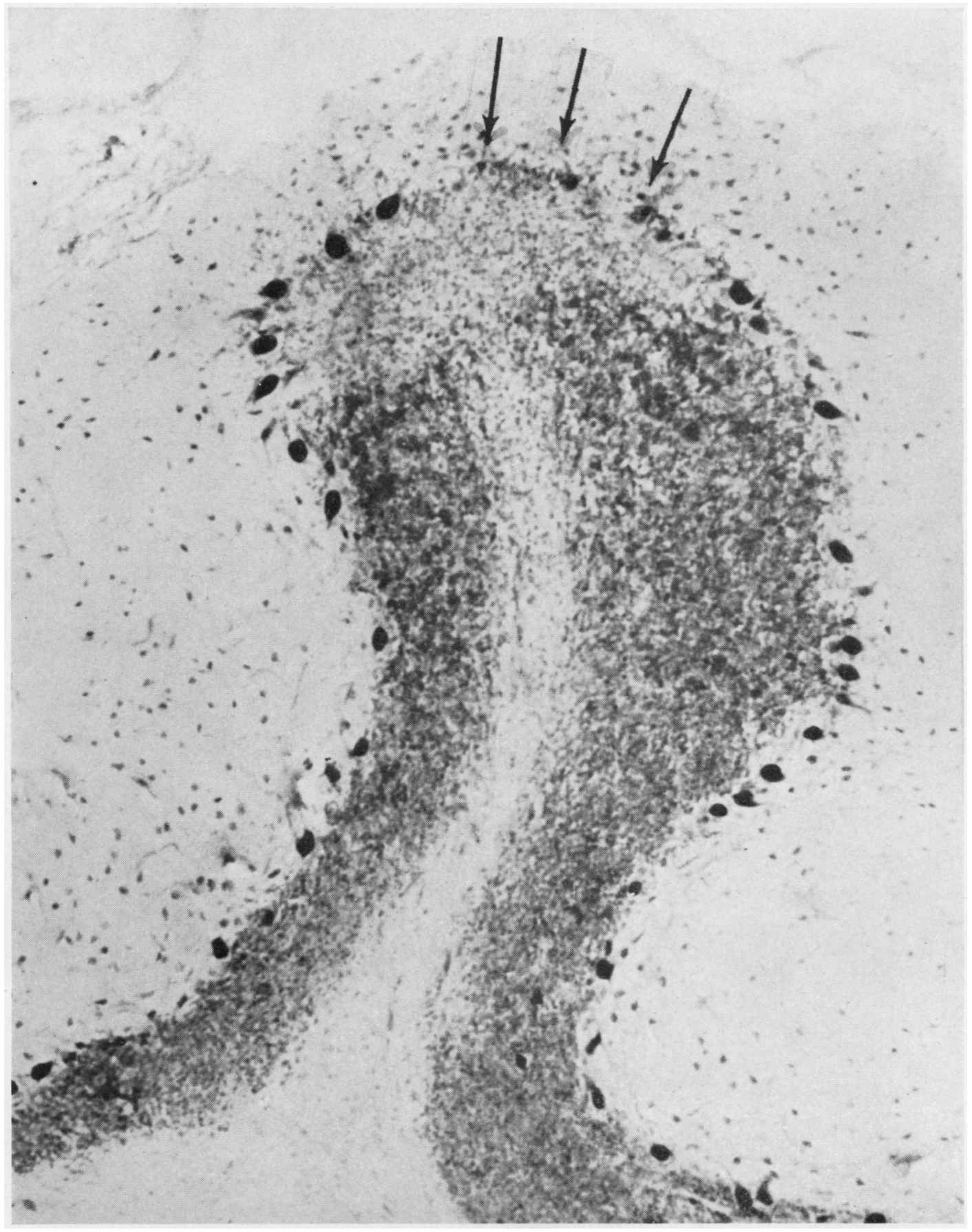

FIG. 3. Dog 19, serial section 4a. Photomicrograph showing the dropping out of granular cells in the convex portion of a cerebellar folia. Bordering this (arrows) are chronically damaged Purkinje neurones. Nissl, $\times 15$. 

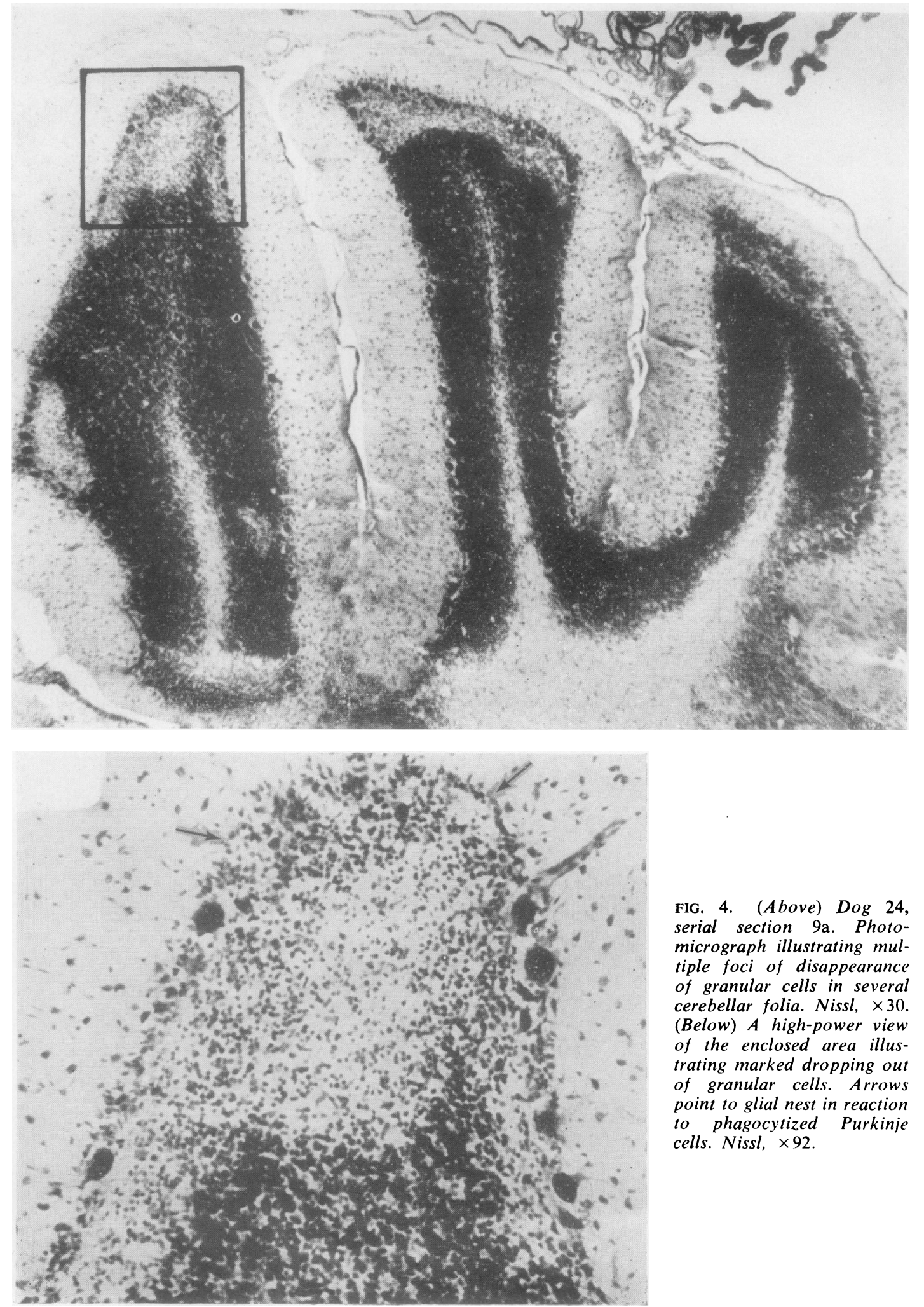

FIG. 4. (Above) Dog 24, serial section 9a. Photomicrograph illustrating multiple foci of disappearance of granular cells in several cerebellar folia. Nissl, $\times 30$. (Below) A high-power view of the enclosed area illustrating marked dropping out of granular cells. Arrows point to glial nest in reaction to phagocytized Purkinje cells. Nissl, $\times 92$. 
histological changes were to all intents and purposes perfectly normal and showed no clinical evidence of neurological abnormality. The two control brains showed no histological change.

\section{DISCUSSION}

In evaluating the results of these experiments, it should be borne in mind that an attempt was being made to test survival whilst imposing to an extreme degree each or all of the three modalities, profound hypothermia, circulatory arrest, and progressive hypoxia, which might be harmful. A review of the literature has not revealed any series of experiments where animals have been subjected to such excessive stresses during profound hypothermia. It is apparent, in the context of this experiment, that profound hypothermia with repeated interruption of the circulation for three periods of one hour is not tolerated by the dog, even if oxygenation is practised in between (group C). It is also true, in terms of immediate survival, that profound hypothermia without circulatory arrest for a period of three hours (group A) and profound hypothermia with circulatory arrest for one hour only (group B), are reasonably well tolerated. When the animal is subjected to hypothermia and then to progressive hypoxia in the presence of a circulation, as in group D, the results are intermediate, and a third of the animals were long-term survivors. These results tend to confirm the earlier results of Lim, Rehder, Harp, Dawson, and Kirklin (1961) and of Gordon et al. (1960), who suggested that profound hypothermia with circulatory arrest for a period of up to one hour is probably safe. The survival figures suggest that profound hypothermia for up to three hours in the presence of a circulation is also reasonably safe, but the neurohistological findings, described above, tend to destroy this hypothesis.

EARLY DEATHS Many of the early deaths were due to pulmonary oedema. Other investigators have noted a high incidence of pulmonary oedema as a complication in animals subjected to profound hypothermia. In the present series of experiments, care was taken to avoid over-perfusion of the lung and of the pulmonary artery, and left atrial pressures and pulmonary flow rates were frequently monitored. Edmunds, Folkman, Snodgrass, and Brown (1963), in a series of experiments in which animals were cooled to profound levels with the use of a heart-lung machine, noted that four died of pulmonary oedema, and they postulate that the incidence of this became lower when ventilation was stopped at $25^{\circ} \mathrm{C}$. Trede, Foote, and Maloney (1961) and Lesage, Sealy, Young, and Lee (1962) also noted a significant incidence of pulmonary complications, and Ashmore, Wakeford, and Harterre (1964), in a series of 19 experiments, found that pulmonary oedema developed in 18 animals. Lesage, Tsuchioka, Koie, and Young (1963), in another series of experiments in which animals were subjected to prolonged periods of profound hypothermia induced by a heart-lung machine, concluded that prolonged perfusion and prolonged hypothermia, particularly when flow was maintained at a high rate, might account for the lung damage. In a later series of experiments one of the present authors has subjected five dogs to profound hypothermia and prolonged perfusion using a heart-lung machine, and none developed pulmonary symptoms (Johnston, Nield, Pritchard, and Hercus, 1965). Further contradictory evidence in this regard is furnished by the absence of pulmonary complications in patients undergoing profound hypothermia for repair of a cerebral aneurysm. In a series of eight patients operated on, none has experienced significant pulmonary difficulty (Gonski, Johnston, Hercus, Rollison. and Nield, 1964). This matches the experience of others who use this technique. It may be that some technical error, which is not apparent at present, accounted for the high incidence of pulmonary complications in the experiments here reported.

NEUROLOGICAL DAMAGE In the present series of experiments neurological changes were seen only when the animals were subjected to profound hypothermia with circulation and oxygenation for a period of three hours. Similar changes were not seen when animals were cooled to $15^{\circ} \mathrm{C}$. and had circulatory arrest for an hour, nor in the long-term survivors in group D, where the animals were subjected to profound hypothermia for two hours with veno-arterial circulation. It may fairly be argued that neurological damage and neurohistological changes occurred in a number of those animals which failed to survive. Most of these were subjected to prolonged periods of anoxia before death and to various other insults, all of which could lead to cerebral damage. In the opinion of the authors, it was felt that these animals would not represent a true picture of the possible cerebral effects which might be produced by the conditions of the experiment alone. It was for this reason that the brains of long-term sur. vivors only were examined. 
There is controversy in the literature concerning the possibility of cerebral damage resulting from profound hypothermia with or without circulatory arrest. Edmunds et al. (1963) reported four deaths from cerebral causes in a series of 29 dogs cooled to $10^{\circ} \mathrm{C}$. using extracorporeal circulation. They concluded that dogs which received a perfusion of Rheomacrodex into the cerebral circulation before circulatory arrest did better and that the damage in the brain was probably due to sludging in the blood. As this is one of the few experimental series in the literature where attention has been paid to neurohistological changes in long-term survivors, a few comments seem justified. Neurological changes were noted in 10 out of 12 animals which were sacrificed at 21 days. The changes were widespread in the cerebral hemispheres and to a lesser extent in the cerebellum and the basal ganglia. The brain damage was frequently apparent to the naked eye, but this was never observed in the present series. The period of circulatory arrest varied from 15 minutes to 60 minutes. The authors comment that cooling was as rapid as possible, and apparently no attention was paid to the gradient across the heat exchanger. This may be highly significant and may be related to the high incidence of brain damage in their group of long-term survivors. White and Donald (1962), on the other hand, found, in a series of experiments in which they produced preferential brain cooling to $15^{\circ} \mathrm{C}$., that complete protection was given as far as cerebral function was concerned for a period of 30 minutes of circulatory arrest. Trede et al. (1961) found that one dog in a series of 16 , when cooled to $10^{\circ} \mathrm{C}$. and arrested for 30 minutes, developed only histological evidence of cerebral oedema. Lesage et al. (1962), in a series of 65 dogs which were cooled to $10^{\circ} \mathrm{C}$. with circulatory arrest for one hour, found that four died during the first week from cerebral damage, but no histological details are given. Donald and Kerr (1964) reported that no cerebral damage had occurred in dogs which were cooled to $10^{\circ} \mathrm{C}$. and arrested for 30 minutes, but found, on the other hand, a very high incidence of abnormal neurological signs (neuropathology to be reported) if the temperature was reduced to $5^{\circ} \mathrm{C}$. or less. Yet Bucknam and Galindo (1961), in a rather similar series of experiments, also reduced the temperature of the animal to $5^{\circ} \mathrm{C}$. and had a very high incidence of survival with a very low incidence of neurological damage.

The evidence is more conflicting when one turns to reports of clinical experience. Dubost et al. (1962), in a series of over 200 patients using $\frac{}{}$ profound hypothermia with extracorporeal circu- $\overline{\bar{c}}$ lation, claim that no patient has suffered neuro- $\vec{\varnothing}$ logical damage. Hickey, Shanahan, Gaffney, and 음 Leahy (1962) and Gordon (1962) each record one के case of brain damage in patients operated on $\overrightarrow{0}$ using the technique of profound hypothermia without an oxygenator. Drew (1961), in over 300 ल open-heart operations, noted brain damage in $\vec{F}$ three patients. These patients were operated on at a time when an efficient new heat exchanger was $-\underset{-}{N}$ first being used, and Drew claims that, by main- ir taining the temperature differential between the $\omega$ ingoing and outcoming blood at $10^{\circ} \mathrm{C}$. or less, $\vec{\circ}$ cerebral damage is unlikely. It is probable that the cooling gradient is one important factor in deter- $\vec{c}$ mining whether brain damage will occur, and $\mathbb{8}$ this is supported by the experimental work of $\underset{\mathbb{D}}{\mathbb{D}}$ Almond, Jones, Snyder, Grant, and Meyer (1964). In their experiments, when the gradient was $20^{\circ} \mathrm{C}$., each $\operatorname{dog}$ showed gross and widespread $\vec{\odot}$ neurological damage. As the gradient was re-尺 duced in successive groups of dogs, the changes. became less, but even when the gradient was aso low as $4-6^{\circ} \mathrm{C}$., there were minimal neurohisto-s logical changes. In the present series of experi-o ments care was taken to avoid a gradient in $\frac{๊}{\Phi}$ excess of $10^{\circ} \mathrm{C}$. between the incoming and out- $\stackrel{D}{\circ}$ going blood. Tubbs (1965), who has a wide $\overrightarrow{\vec{O}}$ experience of profound hypothermia using the 3 Drew technique, is not convinced that any of his patients has suffered cerebral damage from profound hypothermia or circulatory arrest when cold. One patient was subjected to a total of 123 음 minutes of circulatory arrest, in periods of 58 and $\times$ 65 minutes, with complete recovery. Belsey (1965)응 reported 200 open-heart procedures using the Drew technique. One patient developed a Parkin-Oํㄱㅇ sonian tremor after the operation, but in this case, where the patient was suffering from a ventricular septal defect and aortic incompetence, it was felt that the cerebral perfusion was inadequate during cooling. He also rezorded complete recovery after a period of 100 minutes of complete circulatory arrest at $10^{\circ} \mathrm{C}$, and full recovery after three hours' circulatory arrest at $10^{\circ} \mathrm{C}$. in divided $\omega$ periods. Björk and Hultquist (1962), on the other hand, have challenged whether it is ever justifiablec to use profound hypothermia at $10^{\circ} \mathrm{C}$. or less. $\mathbb{D}$ They reported severe cerebral damage in six.+ children, five of them dying from this cause when deep hypothermia in open-heart surgery was used. $\frac{\text { ते }}{\mathbb{Q}}$ In at least three of these patients the rate of cool- $\frac{}{9}$ ing was excessively fast by the standards advised $\stackrel{\mathbb{Q}}{\circ}$ by Drew, and this may have been a factor in the 
cerebral damage. Egerton et al. (1963) had a similar experience to Björk when using profound hypothermia at $8-10^{\circ} \mathrm{C}$. in aortic valve surgery without circulatory arrest. Most of the 16 patients operated on had brain damage, and four died. Examination of the records of these patients again showed that cooling was rapid.

The exact mechanism which may operate in producing cerebral damage when rapid rates of cooling are used is not clear. It has been suggested that it is due to the appearance of microemboli of oxygen in the arterial side of the circulation, but the experimental work of Kaplan, Clark, Fox, Daoud, and Shemtob (1962), who alternated the heat exchanger between the venous and the arterial side of the oxygenator, tends to eliminate this factor. No neurological changes were noted in any of the nine animals which survived the 10 experiments. On the other hand, it is possible that large gradients may exist across segments of brain tissue during rapid cooling and that enough oxygen is not readily available for these warm and metabolically active areas because of shift of the oxygen dissociation curve to the left. Nevertheless, in the present series of experiments where temperatures were carefully controlled, brain damage did occur in two of the animals. The duration and the degree of profound hypothermia may be important in addition to the rate of cooling.

Before ascribing the cause of cerebral changes to any one factor, such as profound hypothermia or circulatory arrest, it must be borne in mind that in many clinical instances of cerebral damage following open-heart surgery a multiplicity of factors may be operating. Brierley (1963) conducted a neurohistological analysis of 11 patients who died between six hours and 11 days after open-heart surgery, having suffered obvious brain damage. Most of these patients were operated on with the assistance of a heart-lung machine, but hypothermia to as low as $20^{\circ} \mathrm{C}$. was frequently used. Unlike the diffuse changes noted by Björk and Hultquist (1962), the histological changes in these patients were focal or geographical in distribution. It was not always possible to determine the aetiology of the cerebral changes, but Brierley considered that air embolism played a part. Several of the patients showed the changes of anoxia and others showed evidence of foam emboli.

The authors would like to draw attention to the absence of clinical features in the two dogs which showed evidence of histological damage on serial section of the brain. It may well be that such changes occur in patients who are apparently well after open-heart surgery.

\section{SUMMARY}

An attempt has been made to differentiate between profound hypothermia, circulatory arrest, and hypoxia as factors which may produce harmful effects when the technique of profound hypothermia and circulatory arrest is used.

It appears that profound hypothermia at $15^{\circ} \mathrm{C}$. with circulatory arrest for one hour is well tolerated. A review of the literature and an analysis of the data from the present study indicate that there is no clear-cut proof that neurological damage will result in these circumstances provided that the rate of temperature change follows prescribed limits.

Profound hypothermia at $10^{\circ} \mathrm{C}$. with repeated interruption of the circulation for three hours and intermittent oxygenation was uniformly fatal in the present series.

Profound hypothermia at $10^{\circ} \mathrm{C}$. with venoarterial circulation for two hours and intermittent oxygenation was reasonably well tolerated.

Profound hypothermia at $10^{\circ} \mathrm{C}$. for a period of three hours resulted in $60 \%$ long-term survival in the present series, but two of the animals had extensive neurohistological changes in the cerebellum.

It is suggested that the duration of profound hypothermia may be a factor in producing brain damage.

On the basis of oxygen consumption studies it is apparent that most of the available oxygen can be used up during one hour of circulatory arrest.

\section{REFERENCES}

Almond, C. H., Jones, J. C., Snyder, H. M., Grant, S. M., and Meyer, B. W. (1964). Cooling gradients and brain damage with deep hypothermia. $J$. thorac. cardiovasc. Surg., 48, 890.

Ashmore, P. G., Wakeford, J., and Harterre, D. (1964). Pulmonary complications of profound hypothermia with circulatory arrest in the experimental animal. Canad. J. Surg., 7, 93.

Belsey, R. (1965). Personal communication.

Björk, V. O., and Hultquist, G. (1960). Brain damage in children after deep hypothermia for open-heart surgery. Thorax, 15, 284. - (1962). Contraindications to profound hypothermia in open-heart surgery. J. thorac. cardiovasc. Surg., 44, 1.

Brierley, J. B. (1963). Neuropathological findings in patients dying after open-heart surgery. Thorax, 18, 291.

Bucknam, C. A., qnd Galindo, A. (1961). Tolerance of circulatory arrest in deep hypothermia by extracorporeal cooling. $J$. Neurosurg., 18, 339.

Donald, D. E., and Kerr, F. W. L. (1964). The response of dogs to perfusion and arrest of circulation at near zero cerebral temperatures. J. surg. Res., 4, 243.

Drew, C. E. (1961). Personal communication. - and Anderson, I. M. (1959). Profound hypothermia in cardiac surgery; report of three cases. Lancet, $1,748$.

- Keen, G., and Benazon, D. B. (1959). Profound hypothermia Lancet, 1, 745 . 
Dubost, C., Blondeau, P., and Piwnica, A. (1962). Extracorporeal circulation during profound hypothermia with prolonged total circulatory arrest. J. cardiovasc. Surg. (Torino), 3, 286.

Edmunds, L. H., Folkman, J., Snodgrass, A. B., and Brown, R. B. (1963). Prevention of brain damage during profound hypothermia and circulatory arrest. Ann. Surg., 157, 637.

Egerton, N., Egerton, W. S., and Kay, J. H. (1963). Neurologic changes following profound hypothermia. Ibid., 157, 366.

Gonski, A., Johnston, J. B., Hercus, V. M., Rollison, R. A., and Nield, J. (1964). Profound hypothermia for intracranial surgery; case report. Med. J. Aust., 1, 318.

Gordon, A. S. (1962). Cerebral blood flow and temperature during deep hypothermia for cardiovascular surgery. J. cardiovasc. Surg. (Torino), 3, 299.

- Jones, J. C., I uddington, L. G., and Meyer, B. W. (1960). Deep hypothermia for intracardiac surgery: experimental and clinical use without an oxygenator. Amer. J. Surg., 100, 332.

Hickey, M. D., Shanahan, W. R., Gaffney, J. D., and Leahy, E. G. (1962). Experimental and clinical experiences with profound hypothermia. J. cardiovasc. Surg. (Torino), 3, 327.

Johnston, J. B., Nield, J. M., Pritchard, G. R., and Hercus, V. M. (1965). Studies of left atrial pressure during cardioplegia produced by profound hypothermia using the closed chest technique. Thorax, 20, 234.
Kaplan, S., Clark, L. C., Fox, R. P., Daoud, G., and Shemtob, A. (1962). Oxygen embolization during deep hypothermia. Arch. Surg., 84, 122.

Lesage, M. A., Tsuchioka, H., Koie, H., and Young, W. G. (1963). Studies on tolerance to prolonged deep hypothermia. Trans. Amer. Soc. art. intern. Org., 9, 230.

- Sealy, W. C., Young, W. G., and Lee, J. M. (1962). Experimental studies on profound hypothermia, induced and reverted $\vec{O}$ with a pump oxygenator. Ann. Surg., 156, 831.

Lim, R. A., Rehder, K., Harp, R. A., Dawson, B., and Kirklin, J. W. $\vec{\omega}$ (1961). Circulatory arrest during profound hypothermia induced by direct blood-stream cooling: an experimental study. Surgery, $49,367$.

Shields, T. W., and Lewis, F. J. (1959). Rapid cooling and surgery a temperatures below $20^{\circ} \mathrm{C}$. Surgery, 46, 164.

Trede, M., Foote, A. V., and Maloney, J. V. (1961). Pathophysiologic ir aspects of profound hypothermia with extracorporeal circulaticn. $\omega$ Arin. Surg., 154, 210.

Tubbs, O. S. (1965). Personal communication.

White, R. J., and Donald, D. E. (1962). Selective hypothermic perfu- 금 sion and circulatory arrest : experiments in the dog brain. Arch. Surg., 84, 292. 